\title{
An outbreak of bilateral photokeratitis among an indoor school event attendees attributable to unshielded mercury vapour and metal halide lights, Eruvadi village, Tirunelveli, Tamil Nadu, South India, 2018
} \author{
M. Rita Hepsi Rani ${ }^{\mathrm{b}}$, B. Premkumar ${ }^{\mathrm{d}}$, Kolandaswamy Karumana Gounder ${ }^{\mathrm{d}}$ \\ a ICMR-National Institute of Epidemiology, Chennai, Tamil Nadu, India \\ ${ }^{\mathrm{b}}$ Department of Ophthalmology, Government Tirunelveli Medical College, Tirunelveli, Tamil Nadu, India \\ ${ }^{c}$ Directorate of Public Health \& Preventive Medicine, Tirunelveli, Tamil Nadu, India \\ ${ }^{\mathrm{d}}$ Directorate of Public Health \& Preventive Medicine, Chennai, Tamil Nadu, India
}

Polani Chandrasekar Rubeshkumar ${ }^{\mathrm{a}}$, P. Manickam, ${ }^{\mathrm{a}, *}$ D. Anandhi ${ }^{\mathrm{b}}$, S. Senthil Kumar ${ }^{\mathrm{c}}$,

\section{A R T I C L E I N F O}

\section{Keywords:}

Photokeratitis

UVR exposure

High-intensity lights

Mercury vapour lights

Metal halide lights

\begin{abstract}
A B S T R A C T
Background: High-intensity lights emit ultraviolet (UV) radiation and are suitable for usage in outdoor settings. Prolonged exposure to UV light causes photokeratitis of the eye. Mid-March 2018, we noted reports of blurred vision among school event attendees in a village in South India. We investigated to confirm the diagnosis and identify reasons.

Methods: A team of ophthalmologists confirmed the diagnosis. We defined the case as the occurrence of any eyerelated symptoms among the school event attendees post-event. We described the cases by time of symptom onset, seating place during the event and type of attendee. We interviewed the cohort of the event attendees for potential exposures. We calculated relative risk (RR) and 95\% Confidence Intervals (CIs) by comparing the incidence of photokeratitis by seating location of the participants from the event dais (where mercury vapour and metal halide lights were fixed) and duration of exposure.

Results: Of 180 attendees, we interviewed 154 (86\%) (excluded four with prior eye diseases) and 111 of them had photokeratitis (74\%). Incidence of photokeratitis was higher among those seated within $6 \mathrm{~m}$ from event dais $(93 \%, 102 / 110)$ than the rest $(23 \%, 9 / 40 ; \mathrm{RR}=4.1 ; 95 \% \mathrm{CI}=2.3$ to 7.3$)$ and among those having more than an hour of exposure ( $82 \%$ vs. $21 \%$; RR $=3.9 ; 95 \% \mathrm{CI}=1.6$ to 9.3 ).

Conclusion: Photokeratitis outbreak among school event attendees in South India was due to exposure to UV light from indoor lights used during the event. We recommended restriction of usage of such lights for indoor events through awareness campaigns and guidelines.
\end{abstract}

\section{Introduction}

Ultraviolet (UV) irradiation is one of the several environmental hazards that may cause inflammatory reactions in eyes, especially cornea. In day-to-day life, everyone is exposed to ultraviolet radiation (UVR). The natural source of UVR is sunlight. Other artificial sources of UVR include sun-tanning beds, welding arcs, photographic flood lamps, lightning, electric sparks, and halogen desk lamps. Ultraviolet (UV) light exposure can cause both erythema and conjunctivitis.

UVR is electromagnetic radiation in wavelengths ranging from 100 to $400 \mathrm{~nm}$ and is divided into three bands: ultraviolet A (UVA) (315-400 nm), ultraviolet B (UVB) $(280-315 \mathrm{~nm})$, and ultraviolet C (UVC) (100-280 nm). Shorter wavelengths of UVR have more energy, and this higher energy raises the potential for ocular damage. ${ }^{2}$ Photokeratitis is a clinical entity characterized by damage to the corneal epithelium due to exposure to UV light from natural or artificial sources. Clinical features of photokeratitis are ocular pain, redness in the eye, photophobia (blepharospasm), foreign body sensation, tearing and blurred vision typically appearing 4-12 h after UV light exposure. ${ }^{3}$ Photokeratitis is also known as UV keratitis, welder's keratitis and snow blindness. $^{4}$

On March 17, 2018, local press reported about 100 persons affected with blurred vision following attendance at a school event on March 16, 2018, at Eruvadi village, Tirunelveli district, Tamil Nadu State in South India. In response, the State Directorate of Public Health and Preventive Medicine deputed its trainee officer undergoing Field Epidemiology

\footnotetext{
*Corresponding author. TNHB, ICMR-National Institute of Epidemiology, Ayapakkam, Chennai, 600077, India.

E-mail address: manickam@nie.gov.in (P. Manickam).
} 
(A):

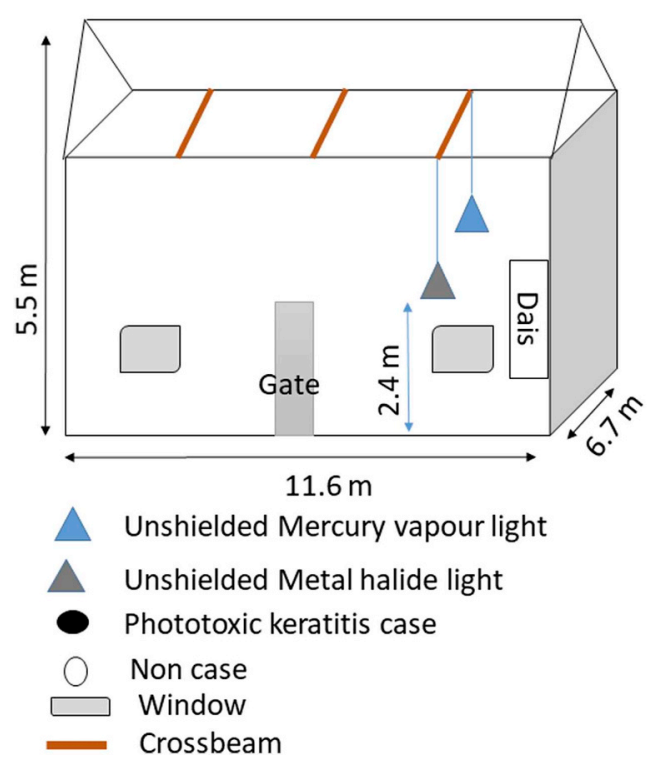

(B):

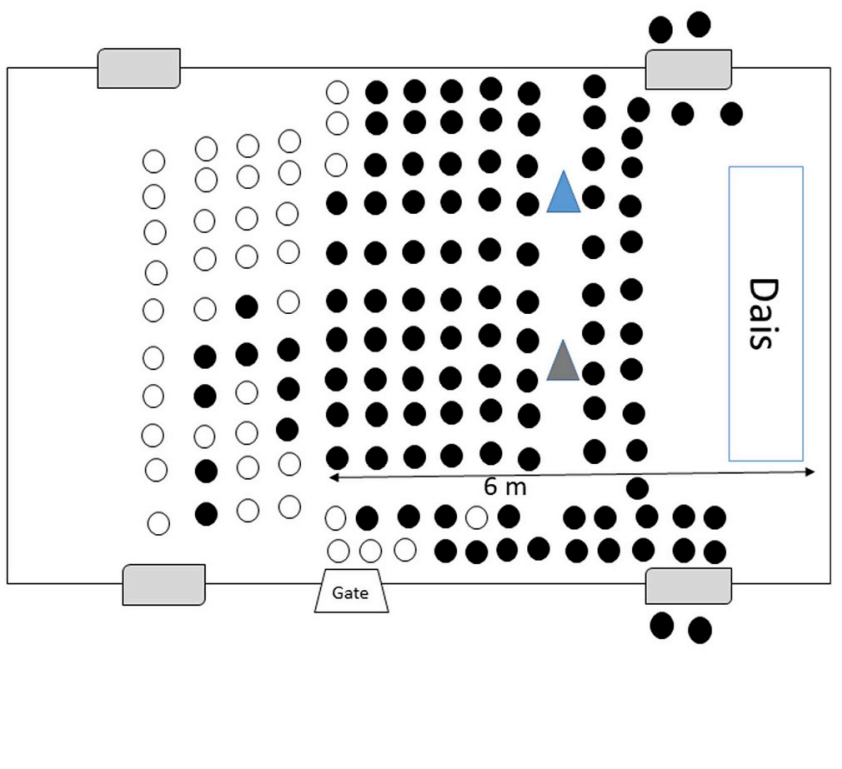

Fig. 1. Description of the place of school event that led to photokeratitis (A) and distribution of cases of photokeratitis by their seating place among event attendees (B), Eruvadi village, Tirunelveli district, Tamil Nadu, South India, March 2018.

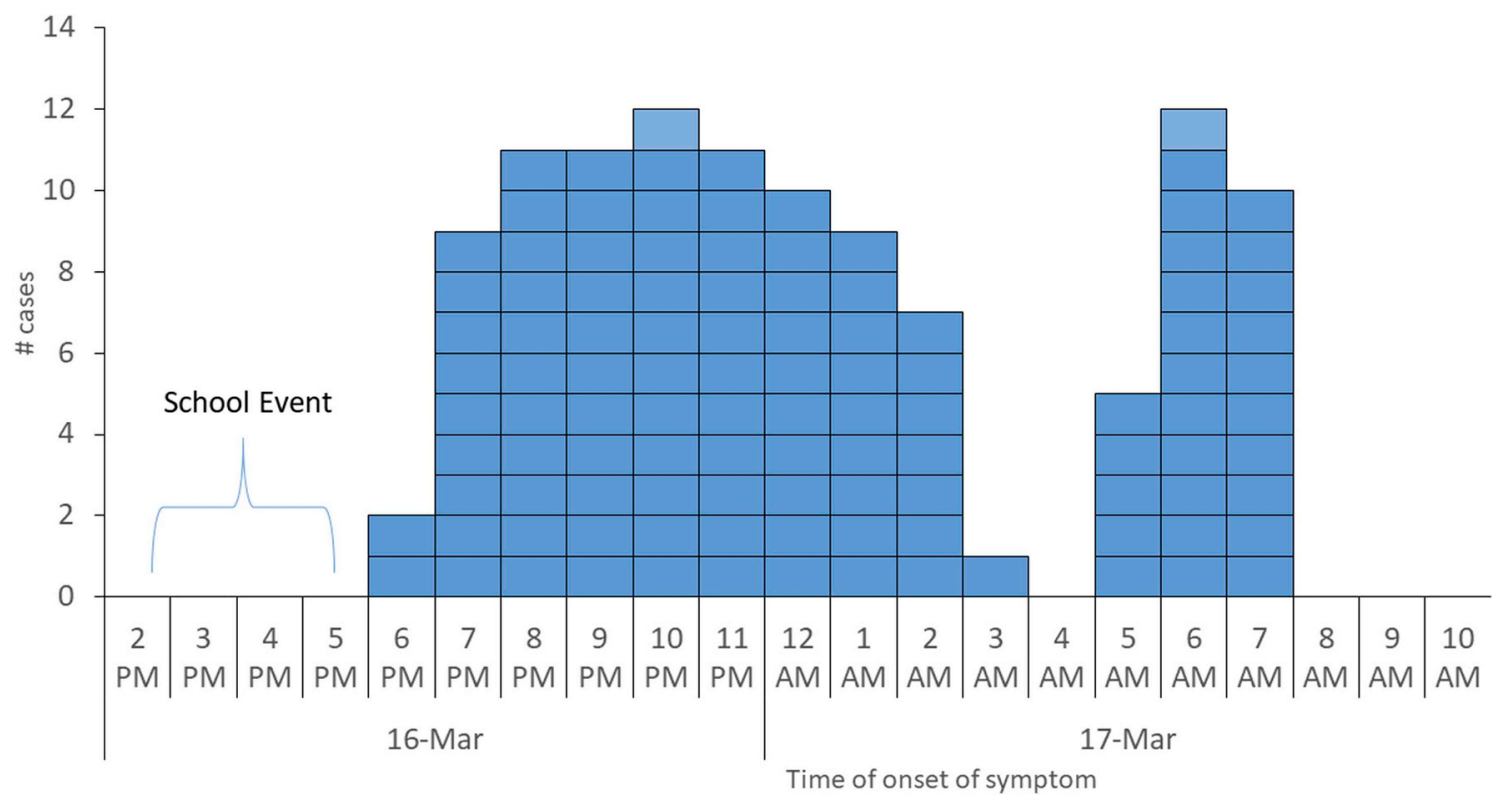

Fig. 2. Incidence of photokeratitis among attendees of school event by the time of onset of signs and symptoms, Eruvadi village, Tirunelveli district, Tamil Nadu, South India, March 2018.

Training Program (FETP) at ICMR-National Institute of Epidemiology (NIE) for investigations in collaboration with the local health officials and the ophthalmologist from the medical college. The team investigated the episode to confirm the diagnosis, describe cases by time, place and person and identify the risk factors.

\section{Methods}

We identified cases through a medical camp in the village. A team of ophthalmologists consisting of two senior ophthalmologists and two junior residents diagnosed the cases by ophthalmic examination in the medical camp. Initially, all the ophthalmologists examined a few cases and arrived at the diagnosis of photokeratitis by consensus based on the clinical presentation and history. Subsequently, they devised an operational case definition to diagnose cases individually. In the event of doubt, they discussed with each other and arrived at a diagnosis. They carried out slit lamp examination and fluorescein staining for those with severe forms of disease. We operationally defined the case with inputs from the ophthalmologists as the occurrence of redness or photophobia or tearing or foreign body sensation or swelling of eyelids or eye pain among the school event attendee since 2 PM (IST) on Mar 16 onwards. We generated a list of event attendees by interview of key stakeholders to collect the information on age, gender, seating location during the event, duration of exposure and time of occurrence of eyerelated symptoms. We calculated the incidence by age, gender, type of attendee, seating location during the event and duration of exposure by using the appropriate denominators. We drew an epidemic curve based on the time of onset of symptoms. We plotted the cases by their seating 
Table 1

Attack rate (\%) of photokeratitis among attendees of school event by age, gender and types of attendees, Eruvadi village, Tirunelveli district, Tamil Nadu, South India, March 2018.

\begin{tabular}{lllll}
\hline Characteristics & & Cases $(n)$ & Attendees $(N)$ & Attack rate $(\%)$ \\
\hline \multirow{2}{*}{ Age group (in years) } & $<5$ & 7 & 10 & 70 \\
& $5-13$ & 58 & 81 & 72 \\
& $14-30$ & 18 & 24 & 75 \\
& $>30$ & 28 & 35 & 80 \\
\hline \multirow{2}{*}{ Gender } & Male & 43 & 58 & 74 \\
& Female & 68 & 92 & 74 \\
\hline \multirow{2}{*}{ Types of attendees } & Students & 60 & 86 & 70 \\
& Teachers & 5 & 5 & 100 \\
& Spectators & 46 & 59 & 78 \\
\hline \multirow{2}{*}{ Total } & & $\mathbf{1 1 1}$ & $\mathbf{1 5 0}$ & $\mathbf{7 4}$ \\
\hline
\end{tabular}

place during the event. We generated the hypothesis based on the descriptive epidemiology, interview of the key informants and non-event attendees. We conducted a retrospective cohort study of the school event attendees to test the hypothesis of photokeratitis following exposure to unsafe lights used during the event. We computed relative risk (RR) and $95 \%$ confidence interval (CI) by comparing attack rates by their seating location during the event and duration of exposure to lights. We calculated the fraction of cases attributable to the exposure in the population (Population attributable risk [PAR]) using the classical formula: the proportion of cases exposed multiplied by the attributable fraction among exposed (RR-1/RR).

\section{Results}

The indoor school event occurred on March 16, 2018 from 2 PM (IST) to $5.30 \mathrm{PM}$ (IST) in a hall with a thatched roof of 78 square meter area $(11.6 \mathrm{~m} \times 6.7 \mathrm{~m})$. The room was mounted with a mercury vapour lamp and one metal halide light at $2.4 \mathrm{~m}$ height in the crossbeam (Fig. 1 (A)).

We generated the list of 180 school event attendees based on the information gathered from the key informants. We examined and interviewed 154 (86\%) event attendees and 33 non-event attendees in the medical camp on 18 March 2018. The ophthalmologists ascertained the clinical outcomes whereas the field epidemiologist obtained exposure history. We could not interview remaining 26 (14\%) event attendees due to their non-availability or inability to reach over the phone. The interviewed attendees were not different from those who could not be interviewed by age and gender. None of the 33 non-event attendees developed a similar disease. Of the 154 event attendees examined, we excluded 4 (3\%) having pre-existing ocular diseases. Of the remaining 150, 74\% developed photokeratitis (111/150). Eleven (7\%) developed symptoms in the first $1 \mathrm{~h}$ following the event (Fig. 2).

More than $80 \%(89 / 111)$ complained of redness, photophobia and foreign body sensation and 18 complained of blurred vision. Based on the clinical severity and symptoms, the ophthalmologists identified 11 patients with severe forms of the disease and carried out slit lamp examination and punctate staining of the corneal epithelium through fluorescein. Four cases developed corneal erosion. After $72 \mathrm{~h}, 95 \%$ of the case-patients became normal. We gathered from the key informants that during the school event that neither food/beverages were served nor there were smoking/fogging related activities happened. Further, they did not report the development of illness among the non-attendees of the event.

The age-specific attack rate was $80 \%$ among those above 30 years ( 28 of 35 ) and $72 \%$ among the children aged $5-13$ years (58 of 81) (Table 1). Seven of 10 children (who were siblings of the school children) under 5 years of age had photokeratitis. The attack rate was the highest among the school children and did not differ by gender (Table 1).

The attack rate was higher among those seated within $6 \mathrm{~m}$ from dais (93\%; 102 of 110$)$ than the others $(23 \% ; 9$ of 40 ; RR $=4.1 ; 95 \%$ $\mathrm{CI}=2.3-7.3$; PAR $=70 \%$ ) (Fig. $1(\mathrm{~B})$ ). Further, the attack rate was significantly higher among those having more than one hour of exposure to the indoor lights $(82 \% ; 107$ of 131) as compared to others $(21 \% ; 4$ of $19 ; \mathrm{RR}=3.9 ; 95 \% \mathrm{CI}=1.6$ to 9.3 ; PAR $=72 \%$ ) (Table 2$)$. During the investigations, we identified that the organizers had used unshielded 400 Watt mercury vapour light and metal halide light.

The Ophthalmologists treated the case-patients with the artificial tears and cycloplegic eye drops. Four case-patients with corneal erosion were referred to the tertiary care hospital. All these patients were followed-up until their complete recovery.

\section{Discussion}

We confirmed an outbreak of photo (or UV) keratitis among the attendees of a school event in a remote locality in South India. We identified that photokeratitis was due to exposure to unshielded mercury vapour and metal halide lights used during that indoor event.

Mercury vapour and metal halide bulbs are bright and long lasting light sources used to illuminate outdoors like a stadium, park and gymnasium. ${ }^{5}$ Metal halide lamps generate an intense light from an an electric arc that travels through a mixture of mercury and metal halide gases. Metal halide lamps are approximately the same colour and temperature as the Sun at noon $(6000 \mathrm{~K})$, and like other high-intensity discharge lamps which contain mercury, generate ultraviolet light. In routine practice, metal halide light should be used along with a UV safety glass cover. Exposure to unshielded or broken metal halide lamps poses a risk of photokeratitis for exposed individuals. ${ }^{5}$

Mercury vapour light has an inner quartz tube which contains mercury discharge and outer glass tube which filters out the harmful UV radiation. ${ }^{5}$ The bulb with a broken outer tube or unshielded inner tube emits the UV radiation which causes eye-related symptoms and skin burns. ${ }^{5,6}$ Photokeratitis can occur with continued natural sunlight exposure. ${ }^{7}$ Previous outbreaks of photokeratitis have been reported subsequent to exposure to mercury vapour lamps and metal halide lamps. ${ }^{6-12}$ In India, the first outbreak of photokeratoconjunctivitis associated with damaged metal halide lamps in the outdoor gathering was reported in 2016. ${ }^{13}$ Our report may be the first report of photokeratitis due to the indoor exposure to unshielded mercury vapour and metal halide lights from South India. The association between exposure to high-intensity lights and photokeratitis meets most of the Hill's guidance points on causality. These include the strength of the association

Table 2

Attack rate (\%) of photokeratitis by selected risk factors, Eruvadi village, Tamil Nadu, South India, March 2018.

\begin{tabular}{|c|c|c|c|c|c|c|c|c|}
\hline \multirow[t]{3}{*}{ Risk factors } & \multicolumn{6}{|c|}{ Incidence of photokeratitis } & \multirow[t]{3}{*}{ Relative risk (RR) } & \multirow[t]{3}{*}{$95 \%$ Confidence interval } \\
\hline & \multicolumn{3}{|c|}{ Among exposed } & \multicolumn{3}{|c|}{ Among unexposed } & & \\
\hline & $\#$ & Total & $\%$ & \# & Total & $\%$ & & \\
\hline Seated within $6 \mathrm{~m}$ from the dais & 102 & 110 & 93 & 9 & 40 & 23 & 4.1 & $2.3-7.3$ \\
\hline More than $1 \mathrm{~h}$ exposure to indoor lights & 107 & 131 & 82 & 4 & 19 & 21 & 3.9 & $1.6-9.3$ \\
\hline
\end{tabular}


that was statistically significant, temporality and consistency with that of results from published studies. Further, three-fourth of the cases in the population were explained by the indoor light exposure alone. However, the association with long-term sequelae such as corneal neuropathy needs further documentation. ${ }^{14}$

\section{Limitations}

Our study findings could suffer from a few limitations. Firstly, bias in the selection of participants could have led to under-estimation of the attack rate. This could be due to interview of $86 \%$ of the total number of event attendees and the voluntary nature of attendance at the medical camp. However, due to the serious nature of the illness and the kind of attention generated by the event, it is unlikely that "case-patients" would not have sought attention and we failed to include them. Therefore, it is less likely that we would have under-estimated the incidence as well as the strength of association. Secondly, we could have had information bias for the ascertainment of exposure as well as the outcome. For instance, the seating place of the participant might have introduced non-differential misclassification. This error could have led to under-estimation of the strength of the association. However, despite such bias, the magnitude of the association was beyond chance. Misclassification of outcome (photokeratitis) by the ophthalmologists is less likely since the exposure status of case-patients was independently ascertained by the trainee officer. Finally, we could not confirm photokeratitis in all the cases through slit-lamp examination and that may introduce a lack of objectivity. However, we could establish the epidemiological linkage between the confirmed cases and the rest in terms of clinical features and the epidemiological features of the onset of the event by the person (among school event attendees), time (short duration) and place (within the village). Therefore, misclassification of outcomes may have been limited in nature. Overall, the evidence based on epidemiological linkage was sufficient to warrant public health action.

\section{Conclusion(s)}

Based on findings, we confirmed that the occurrence of photokeratitis among school event attendees in South India was associated with exposure to unshielded mercury vapour lamp and metal halide lamp used during the event. In India, metal halide lamps are routinely used for large events in stadium, auditorium and convention halls. Currently, there are no guidelines exist to regulate the lights usage and exposure in India. In the absence of any guidelines, based on the outbreak experience, we drafted guidelines for adoption by state health authorities. In the draft guidelines, we recommended restricting usage of high-intensity lights to indoor events through awareness campaigns and enforcement of guidelines. Disease surveillance system usually have a focus on communicable diseases, therefore, need to have the flexibility to incorporate rapid identification and reporting of such events.

\section{Declaration of interests}

None.

\section{Conflict of interest}

The authors do not have any conflict of interests.

\section{Authors contribution}

Rubeshkumar Polani Chandrasekar and Manickam Ponnaiah designed, collected, analysed data, reviewed literature and wrote the manuscript. Anandhi D. and Rita Hepsi Rani M. were involved in clinical diagnosis and management, data collection and revising the manuscript. Senthil Kumar S contributed to data collection and revising manuscript. Premkumar B. and Kolandaswamy Karumana Gounder provided inputs for data collection, interpretation and revising the manuscript.

\section{Funding}

This research did not receive any specific grant from funding agencies in the public, commercial, or not-for-profit sectors.

\section{Ethics committee approval}

This investigation was a rapid response to the public health emergency by the Directorate of Public Health and Preventive Medicine, Government of Tamil Nadu, India. As per the existing Indian norms, such response investigations did not require approval from the Institutional Ethics Committee. Informed consent was not obtained from the case-patients, as these interviews were conducted as a part of public health response activity. Measures were taken to ensure the confidentiality of the information provided during the interview and to secure the collected data.

\section{Acknowledgements}

We thank Prof. K.Shantharaman, Government Tirunelveli Medical College, Tamil Nadu, India for facilitating technical support.

\section{Appendix A. Supplementary data}

Supplementary data to this article can be found online at https:// doi.org/10.1016/j.cegh.2019.03.004.

\section{References}

1. Harmful effects of ultraviolet radiation. Council on Scientific Affairs. J Am Med Assoc. 1989 Jul 21;262(3):380-384.

2. van Norren D, Gorgels TGMF. The action spectrum of photochemical damage to the retina: a review of monochromatic threshold data. Photochem Photobiol. 2011 Aug;87(4):747-753.

3. Cullen AP. Photokeratitis and other phototoxic effects on the cornea and conjunctiva. Int J Toxicol. 2002 Nov;21(6):455-464.

4. Willmann G. Ultraviolet keratitis: from the pathophysiological basis to prevention and clinical management. High Alt Med Biol. 2015 Dec;16(4):277-282.

5. Health $\mathrm{C}$ for D and R. Alerts and notices - ultraviolet radiation burns from high intensity metal halide and mercury vapor lighting remain a public health concern. . [cited 2018 Mar 24]. Available from:. https://www.fda.gov/RadiationEmittingProducts/RadiationSafety/AlertsandNotices/ucm116540.htm.

6. Mazzuckelli LF, MacDonald PDM, Langley RL, Howell RJ. Erythema and conjunctivitis: investigation of an outbreak in a school gymnasium caused by unintentional exposure to ultraviolet radiation from metal halide lamps. J Occup Environ Hyg. 2007 Mar 26;4(5):D46-D49.

7. Izadi M, Jonaidi-Jafari N, Pourazizi M, Alemzadeh-Ansari M, Hoseinpourfard M. Photokeratitis induced by ultraviolet radiation in travelers: a major health problem. $J$ Postgrad Med. 2018;64(1):40-46.

8. Halperin W. Conjunctivitis and skin erythema. Outbreak caused by a damaged highintensity lamp. JAMA, J Am Med Assoc. 1978 Oct 27;240(18):1980-1981.

9. Kwon D-H, Moon J-D, Park W-J, et al. Case series of keratitis in poultry abattoir workers induced by exposure to the ultraviolet disinfection lamp. Ann Occup Environ Med. 2016 Jan 15;28:3.

10. Mangan MS, Arıcı C, Atalay E, Tanyıldız B, Oruçoğlu F. Four cases of pediatric photokeratitis present to the emergency department after watching the same Theater Show. Turk J Ophthalmol. 2015 Oct;45(5):226-228.

11. Banerjee S, Patwardhan A, Savant VV. Mass photokeratitis following exposure to unprotected ultraviolet light. J Public Health. 2003 Jun 1;25(2):160.

12. Kirschke DL, Jones TF, Smith NM, Schaffner W. Photokeratitis and UV-radiation burns associated with damaged metal halide lamps. Arch Pediatr Adolesc Med. 2004 Apr 1;158(4):372-376.

13. Wagh V, Jamadar B, Murhekar M. Notes from the field: photokeratoconjunctivitis outbreak associated with damaged metal halide lamps — Maharashtra state, Western India, June 2016. MMWR Morb Mortal Wkly Rep. 2016 Nov 11;65(44):1238-1239.

14. Yam JCS, Kwok AKH. Ultraviolet light and ocular diseases. Int Ophthalmol. 2014 Apr;34(2):383-400. 